\title{
Polymorphism and Balancing Selection of MHC Class II DAB Gene in 7 Selective Flounder (Paralichthys olivaceus) Families
}

\author{
Min Du, ${ }^{1,2,3}$ Song-lin Chen, ${ }^{1}$ You Liang, ${ }^{1}$ Lei Wang, ${ }^{1}$ Feng-tao Gao, ${ }^{1}$ \\ Yang Liu, ${ }^{1}$ and Xiao-Lin Liao ${ }^{1}$ \\ ${ }^{1}$ Key Lab for Sustainable Utilization of Marine Fisheries Resources, Ministry of Agriculture, Yellow Sea Fisheries Research Institute, \\ Chinese Academy of Fishery Sciences, Nanjing Road 106, Qingdao 266071, China \\ ${ }^{2}$ College of Aqua-life Science and Technology, Shanghai Ocean University, Shanghai 200090, China \\ ${ }^{3}$ Honghe University, Yunnan Province, Mengzi, 661100, China \\ Correspondence should be addressed to Song-lin Chen, chensl@ysfri.ac.cn
}

Received 15 January 2011; Revised 28 April 2011; Accepted 30 May 2011

Copyright (๑) 2011 Min Du et al. This is an open access article distributed under the Creative Commons Attribution License, which permits unrestricted use, distribution, and reproduction in any medium, provided the original work is properly cited.

In order to determine the genetic variation of the MHC class IIB exon2 allele in the offspring, 700 fry from seven families of Japanese flounder challenged with $V$. anguillarum were studied, and different mortality rates were found in those families. Five to ten surviving and dead fry from each of the seven families were selected to study the MHC class II B exon2 gene with PCR and a direct sequencing method. One hundred and sixteen different exon2 sequences were found and 116 different alleles were identified, while a minimum of four loci were revealed in the MHC class II B exon2 gene. The ratio $\left(d_{N} / d_{S}\right)$ of nonsynonymous substitution $\left(d_{N}\right)$ to synonymous substitutions $\left(d_{\mathrm{S}}\right)$ in the peptide-binding region (PBR) of the MHC class IIB gene was 6.234, which indicated that balancing selection is acting on the MHC class IIB genes. The MHC IIB alleles were thus being passed on to their progeny. Some alleles were significantly more frequent in surviving than dead individuals. All together our data suggested that the alleles Paol-DAB* 4301, Paol-DAB* 4601, Paol-DAB*4302, Paol-DAB*3803, and Paol-DAB* 4101 were associated with resistance to $V$. anguillarum in flounder.

\section{Introduction}

Genes of the major histocompatibility complex (MHC) are characterized by extremely high levels of polymorphism in cell surface glycoprotein class I and II molecules. They play a primary role in both innate and adaptive immunity by presenting self- and foreign peptides to $\mathrm{T}$ cells $\left(\mathrm{CD}^{+} \mathrm{T}\right.$ cells or $\mathrm{CD}^{+} \mathrm{T}$ cells) [1] in vertebrate organisms, and subsequently initiate a specific immune response [2].

Unlike the case in mammals, MHC class I and class II regions in teleost fish are situated on different linkage groups and therefore do not form a complex [3-5]. MHC genes in fish have received considerable attention since the first teleost fish MHC gene fragments were isolated from carp (Cyprinus carpio L.) by Hashimoto et al. [6]. MHC class I and class II both contain a peptide-binding region (PBR). The exon2 sequence of the MHC class II B gene is known to cover the majority of the polymorphism and has been considered a candidate molecular marker for an association between these alleles and resistance/susceptibility to various diseases [7].
There are reports of polymorphism of exon 2 of MHC class II $B$ gene in a number of vertebrates, including mammals $[8,9]$, reptiles [10, 11], amphibians [12], and fish [13-15].

It is believed that balancing selection maintains this large variation, which includes frequency-dependent selection, over dominant selection, and positive selection across habitats, but the exact nature of the selection process continues to be a topic of debate [16-18].

Japanese flounder (Paralichthys olivaceus) is an economically important marine fish in China, and a few studies have been reported on the MHC class II B gene $[15,19,20]$. For example, Srisapoome et al. [19] reported the expression level of MHC II B cDNA. Zhang et al. [20] studied polymorphism in the flounder MHC class II B gene. Xu et al. [15] demonstrated an association between MHC class II B exon2 and resistance to $V$. anguillarum in 60 families of Japanese flounder, and thus the alleles associated with resistance and susceptibility to $V$. anguillarum were discovered.

In order to breed a new flounder strain with enhanced disease resistance and growth rate, selective breeding has 
been carrying out, since 2002. Three basic populations (i.e., Japanese (JS), Resistance (RS), and Yellow Sea (YS) populations) were developed in 2002 and 2003 [21]. JS were imported from Japan in 2003; RS were obtained from natural selection and artificial challenge with Vibrio anguillarum; YS were captured from the Yellow Sea in 2003. These were called "generation 0 " $\left(\mathrm{G}_{0}\right)$. A little more than three years later, in March, 2007, the fry of the three basic populations that had become sexually mature were selected to mate and produced 63 full-sib families or half-sib families and were designated "generation 1" $\left(\mathrm{G}_{1}\right)$. After artificial challenge with Vibrio anguillarum, the survival percentage ratios (Mean \pm S.D. (\%)) of the families studied (family 0751, family 0768, family 0743 , family 0750 , and family 0719 ) were $54.13 \pm$ $1.23,62.08 \pm 22.52,7.27 \pm 3.57,64.05 \pm 0.74$, and $30.86 \pm$ 7.22 , respectively; the survival ratio of the resistance families was not available. Two years later, in March, 2009, sexually mature fish were selected for mate (generation $2\left(G_{2}\right)$ ) and artificial challenge were performed, with the result that the survival ratios of the families were different.

The fry of the next generation exhibited clear genetic information within each family. In this study, their offspring were infected with $V$. anguillarum and their survival rate was recorded. We amplified and directly sequenced MHC class II $\mathrm{B}$ exon2 in order to estimate the number of MHC class II loci, assess the MHC polymorphism of selected individuals, and test for balancing selection, as well as to discover the pattern of the inheritance of the allele in seven families of Japanese flounder.

\section{Materials and Methods}

2.1. Experimental Design. According to a previous study [15], the fish from family 0768 and family 0751 had the Paol$D A B^{*} 4301$ allele, while the fish from the 0743, R7, 0750, and 0719 families did not. The Paol-DAB* 4301 allele in flounder was associated with resistance to $V$. anguillarum. The survival ratio of families 0768 and 0751 was higher than that of the 0743, R7, 0750, and 0719 families. Males and females from $G_{1}$ in these six families were selected as parental fish to propagate the offspring in $\mathrm{G}_{2}$ (Figure 1). The brood fish in $\mathrm{G}_{0}$ were involved in our previous study [21]. Families 92, 102 , and 5 were offspring of self-cross of families 0751,0768 , and 0750, respectively, (Figure 1). Family 101 had one dam from family 0743 crossed with one sire from family 0751 . Family 41 had a dam from family R7 crossed with one sire from family 0768 . Family 75 were the offspring of one dam from family 0750 and one sire from family 0743 , and family 104 were the offspring of one dam from family 0719 and one sire from family 0768 . A total of 7 full-sib families of Japanese flounder were established, as reported by Chen et al. [21] and were reared at the fish farming factory at Haiyang city, Shandong province. The fry were fed a commercial diet and were kept in separate tanks.

2.2. Challenge Experiment. Approximately 100 individuals from each family and a total of 700 offspring from 7 full-sib families were used in the challenge experiment.
TABLE 1: Numbers of the dead/surviving individuals when infected with the $V$. anguillarum were selected from seven families of Japanese flounder.

\begin{tabular}{|c|c|c|c|}
\hline \multirow{2}{*}{ Family } & \multicolumn{2}{|c|}{ Individuals per family } & \multirow{2}{*}{ Total } \\
\hline & Dead & Surviving & \\
\hline Family 101 & 20 & 20 & 40 \\
\hline Family 104 & 20 & 20 & 40 \\
\hline Family 5 & 10 & 10 & 20 \\
\hline Family 41 & 10 & 10 & 20 \\
\hline Family 75 & 10 & 10 & 20 \\
\hline Family 92 & 10 & 10 & 20 \\
\hline Family 102 & 10 & 10 & 20 \\
\hline Total & 90 & 90 & 180 \\
\hline
\end{tabular}

The body weight of the fish analyzed was $12-17 \mathrm{~g}$. The test fish of each family were kept in a separate tank at the same farming factory under flow-through conditions with a fresh water supply at $20 \pm 0.5^{\circ} \mathrm{C}$ and were fed twice daily. The $V$. anguillarum isolated by our laboratory was used in the challenge test and prechallenge experiment, and the median lethal concentration was determined according to $\mathrm{Xu}$ et al. [15]. Dead fish were recorded and collected every day. The challenge experiment was terminated 14 days after infection. The survival ratio (Mean \pm S.D. (\%)) of families 5, 41, 102, $75,101,92$, and 104 was $78.3 \pm 7.43,32.2 \pm 3.61,31.9 \pm$ $22.36,37.9 \pm 9.44,33.4 \pm 3.7,21.8 \pm 11.97$, and $55.6 \pm 1.83$, respectively. In addition to the daily recording of the fish that had died, fin clippings were taken from all fish and were stored individually in absolute ethanol.

2.3. Sampling and DNA Isolation. Fin samples from the top 10 (families 5, 41, 75, 92, and 102, resp.) or 20 (families 101,104, resp.) individuals to die and the top 10 (families $5,41,75,92$, and 102, resp.) or 20 (families 101 and 104, resp.) surviving individuals from each family were collected from the challenge trials (Table 1). Table 1 shows the number of the dead fish. Surviving individuals were selected from the seven families of Japanese flounder in the study. Genomic DNA was extracted from the dorsal or caudal fin tissue of the dead and surviving fry via a modified phenol-chloroform method [22]. The integrity of the DNA was analyzed on a $1 \%$ agarose gel containing $0.5 \% \mu \mathrm{g} / \mathrm{mL}$ ethidium bromide by electrophoresis and visualized under UV light. The concentrations of DNA were measured using a GENEQUANT Pro (Pharmacia Biotech Ltd.) RNA/DNA spectrophotometer. Finally, DNA was adjusted to $100 \mathrm{ng} / \mu \mathrm{L}$ and stored at $-20^{\circ} \mathrm{C}$.

2.4. Primer Design and Polymerase Chain Reaction (PCR). Two oligonucleotides of the gene-specific primers: fMPN (5-CTCCCTCTTCTTCATCACGG T-3) and fMPC (5ACACACTCACCTGACTTCGT-3) were used for amplifying the flounder MHC II B sequences, which were designed according to the flounder cDNA sequences reported [20] and published communications [15]. The forward primer for class II B is based on the end of exon1 sequence, 


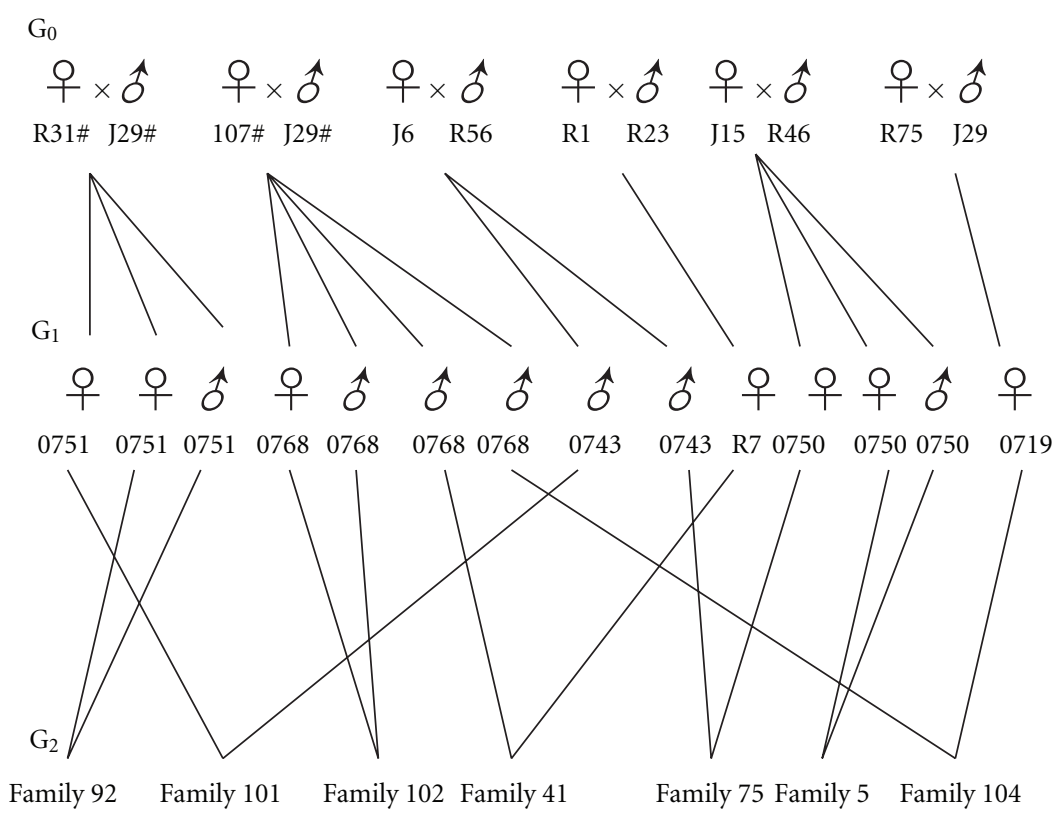

FIgURE 1: The pedigree denotes the families in generation $G_{2}$ with parents in $G_{1}$ and grandparents in the $G_{0}$.

and the reverse primer for class II $B$ is on the end of exon2 sequence, respectively. Polymerase chain reaction (PCR) was performed in a total volume of $25 \mu \mathrm{L}$, which consisted of $100 \mathrm{ng}$ template DNA, $2.5 \mu \mathrm{L}$ of $10 \times \mathrm{Taq}$ polymerase buffer (TransGen Biotech), $1.5 \mathrm{mM} \mathrm{MgCl}_{2}$, $0.2 \mathrm{mM}$ deoxynucleotide triphosphate, $0.2 \mu \mathrm{M}$ each of the forward and reverse primers, and 1 unit of Taq polymerase (TransGen Biotech). The amplification conditions were optimized to reduce the nonspecific amplification [23]. Thermocycling was conducted on a Peltier Thermal Cycler (PTC-200) and the amplification schedule was $94^{\circ} \mathrm{C}$ for 5 minutes, 30 cycles of $94^{\circ} \mathrm{C}$ for $40 \mathrm{~s}, 52^{\circ} \mathrm{C}$ for 40 seconds, $72^{\circ} \mathrm{C}$ for 50 seconds, and finally $72^{\circ} \mathrm{C}$ for 10 minutes. The Molecular Imager Gel Doc XR system (Bio-rad) was used to check for integrity and visualize the PCR products by electrophoresis on a 1\% agarose gel. The amplified fragments exhibited one distinct band with an approximate length of 500 bp.

2.5. Cloning and Sequencing. PCR products were excised and then purified with the QIAEX II gel extraction kit (Qiagen). According to the standard protocol, the purified products were ligated into a PBS-T vector with a TA cloning kit (Takara) and then cloned into TOP 10 Escherichia coli competent cells (TransGen Biotech). Positive clones were screened in PCR reactions with the cloning primers T7 and M13R. The PCR products for appropriately sized clones were cleaned with a Qiaquick PCR purification column (Qiagen) before cycle sequencing with a Big Dye Terminator cyclesequencing kit following the manufacturer's instructions on an ABI 3730 automated sequencer (Applied Biosystems, Foster City, CA, USA). All of the alleles shown in the present study were confirmed by sequencing a minimum of five times in ten individuals from five of the families, but up to 10 times or more in twenty individuals from two of the families.
2.6. Genotyping, Sequence Analysis, and Statistical Tests. MHC gene sequences were aligned using DNAMAN software. Comparison of these nucleotide sequences and deduced amino acid sequences was performed using the MEGA4.0 program [24]. The relative rates of synonymous $\left(d_{S}\right)$ and non-synonymous $\left(d_{N}\right)$ substitution were determined according to Nei and Gojobori [25] and corrected for multiple hits (Jukes and Cantor) [26] using MEGA4.0. The frequency of polymorphism was analyzed using all of the alleles in the program by means of DnaSP4.0 [27] and DAMBE [28] with Jukes-Cantor distances. Statistical analysis was obtained using SPSS13.0. Allele frequency discrepancies were verified using Fisher's exact test and the significance level [29] was determined for every individual $(n=180)$ and every family $(n=7)$.

\section{Results}

The average mortality ratio was $66.65 \pm 24.31$ (the Mean \pm S.D. (\%)), which was calculated 14 days after the bacterial infection in the 7 families. In this study, we verified 116 distinct MHC class II nucleotide sequences from 180 individuals of the seven flounder families (Table 1). Among these sequences, 72 sequences were present only once, and 17 sequences were the same as in previous reports [15], that is, Paol-DAB*0101, Paol-DAB*0301, Paol-DAB*0801, PaolDAB* 0901, Paol-DAB* 2201, Paol-DAB*3201, Paol-DAB* 35 01, Paol-DAB*3801, Paol-DAB*3803, Paol-DAB*3804, Paol$D A B^{*}$ 3805, Paol-DAB*4302, Paol-DAB*0102, Paol-DAB* 2202, Paol-DAB* 0502, Paol-DAB* 4101, and Paol-DAB* 4301. 99 sequences were newly discovered in the present study and were deposited in GenBank (accession no. HQ634973HQ635071; Table 2). 
TABLE 2: The alleles and GenBank accession numbers.

\begin{tabular}{|c|c|c|c|c|c|}
\hline Allele & GenBank accession no. & Allele & GenBank accession no. & Allele & GenBank accession no. \\
\hline Paol-DAB*0103 & HQ634973 & Paol-DAB* 2212 & HQ635006 & Paol-DAB* 4901 & HQ635039 \\
\hline Paol-DAB*0104 & HQ634974 & Paol-DAB* 2213 & HQ635007 & Paol-DAB* 5001 & HQ635040 \\
\hline Paol-DAB*0105 & HQ634975 & Paol-DAB* 2214 & HQ635008 & Paol-DAB* 5101 & HQ635041 \\
\hline Paol-DAB*0106 & HQ634976 & Paol-DAB* 2215 & HQ635009 & Paol-DAB* 5102 & HQ635042 \\
\hline Paol-DAB* 0107 & HQ634977 & Paol-DAB* 2216 & HQ635010 & Paol-DAB* 5201 & HQ635043 \\
\hline Paol-DAB*0108 & HQ634978 & Paol-DAB* 2217 & HQ635011 & Paol-DAB* 5202 & HQ635044 \\
\hline Paol-DAB*0109 & HQ634979 & Paol-DAB*3204 & HQ635012 & Paol-DAB*5203 & HQ635045 \\
\hline Paol-DAB*0110 & HQ634980 & Paol-DAB*3205 & HQ635013 & Paol-DAB*5301 & HQ635046 \\
\hline Paol-DAB*0111 & HQ634981 & Paol-DAB*3206 & HQ635014 & Paol-DAB*5401 & HQ635047 \\
\hline Paol-DAB*0112 & HQ634982 & Paol-DAB*3207 & HQ635015 & Paol-DAB*5402 & HQ635048 \\
\hline Paol-DAB*0113 & HQ634983 & Paol-DAB*3208 & HQ635016 & Paol-DAB*5501 & HQ635049 \\
\hline Paol-DAB*0114 & HQ634984 & Paol-DAB*3209 & HQ635017 & Paol-DAB*5601 & HQ635050 \\
\hline Paol-DAB*0115 & HQ634985 & Paol-DAB* 3502 & HQ635018 & Paol-DAB* 5701 & HQ635051 \\
\hline Paol-DAB*0116 & HQ634986 & Paol-DAB*3806 & HQ635019 & Paol-DAB* 5801 & HQ635052 \\
\hline Paol-DAB*0117 & HQ634987 & Paol-DAB* 4307 & HQ635020 & Paol-DAB* 5802 & HQ635053 \\
\hline Paol-DAB*0118 & HQ634988 & Paol-DAB* 4308 & HQ635021 & Paol-DAB* 5803 & HQ635054 \\
\hline Paol-DAB*0119 & HQ634989 & Paol-DAB* 4309 & HQ635022 & Paol-DAB*5804 & HQ635055 \\
\hline Paol-DAB*0120 & HQ634990 & Paol-DAB* 4310 & HQ635023 & Paol-DAB* 5901 & HQ635056 \\
\hline Paol-DAB* 0121 & HQ634991 & Paol-DAB* 4311 & HQ635024 & Paol-DAB*6001 & HQ635057 \\
\hline Paol-DAB* 0122 & HQ634992 & Paol-DAB* 4312 & HQ635025 & Paol-DAB*6101 & HQ635058 \\
\hline Paol-DAB*0123 & HQ634993 & Paol-DAB* 4313 & HQ635026 & Paol-DAB* 6201 & HQ635059 \\
\hline Paol-DAB*0304 & HQ634994 & Paol-DAB* 4314 & HQ635027 & Paol-DAB* 6301 & HQ635060 \\
\hline Paol-DAB* 0802 & HQ634995 & Paol-DAB* 4315 & HQ635028 & Paol-DAB* 6401 & HQ635061 \\
\hline Paol-DAB*0902 & HQ634996 & Paol-DAB* 4316 & HQ635029 & Paol-DAB* 6402 & HQ635062 \\
\hline Paol-DAB* 0903 & HQ634997 & Paol-DAB* 4317 & HQ635030 & Paol-DAB* 6501 & HQ635063 \\
\hline Paol-DAB* 2204 & HQ634998 & Paol-DAB* 4601 & HQ635031 & Paol-DAB* 6601 & HQ635064 \\
\hline Paol-DAB*2205 & HQ634999 & Paol-DAB* 4602 & HQ635032 & Paol-DAB* 6801 & HQ635065 \\
\hline Paol-DAB*2206 & HQ635000 & Paol-DAB* 4603 & HQ635033 & Paol-DAB* 6901 & HQ635066 \\
\hline Paol-DAB* 2207 & HQ635001 & Paol-DAB* 4604 & HQ635034 & Paol-DAB* 7001 & HQ635067 \\
\hline Paol-DAB* 2208 & HQ635002 & Paol-DAB* 4605 & HQ635035 & Paol-DAB* 7101 & HQ635068 \\
\hline Paol-DAB*2209 & HQ635003 & Paol-DAB* 4701 & HQ635036 & Paol-DAB* 7201 & HQ635069 \\
\hline Paol-DAB* 2210 & HQ635004 & Paol-DAB* 4801 & HQ635037 & Paol-DAB* 7301 & HQ635070 \\
\hline Paol-DAB* 2211 & HQ635005 & Paol-DAB* 4802 & HQ635038 & Paol-DAB* 6701 & HQ635071 \\
\hline
\end{tabular}

The new alleles detected in this study were based on the deduced amino acid sequences and designated based on the rules reported previously $[15,30-32]$. For example, in Paol$D A B^{*} 0103$, Paol refers to Paralichthys olivaceus, D to class II, A to the family designation, and $\mathrm{B}$ to the $\beta$ chain-encoding genes. In the four digits after the asterisk, the first two digits refer to the major type (i.e., alleles that differ by at least five amino acid substitutions), and the last two digits to the subtype (i.e., alleles that differ by less than five amino acid substitutions within a single major type).

3.1. MHC Class II B Sequence Diversity. The length of the amplified MHC class II sequence was $407 \mathrm{bp}$. The sequences covered 91 amino acid residues of the MHC class II B exon2 and complete intron 1 (84/96 bp, including a $12 \mathrm{bp}$ repeat loci) [15]. There were no frame-shift mutations or stop codons in these alleles. There were 151 polymorphic sites across the 116 different MHC class II exon2 sequences. The average number of nucleotide differences $(k)$ was 20.84, and the nucleotide diversity value $\left(P_{i}\right)$ for these sequences was 0.07634 . Among the individuals of the seven families, five ( 10 individuals from families $5,41,75,92,102$, resp.) or ten $(20$ individuals from family 101, 104, resp.) clones per individual were sequenced. Only one sequence was present in five clones per individual from 25 individuals of families 102, 92, 75, 41, and 5; two sequences were detected in five or ten clones per individual from 71 individuals; three sequences were found in five or ten clones per individual from 57 individuals; four sequences were present in five or ten clones per individual from 18 individuals; five sequences were only detected in ten clones per individual from 5 individuals from family 101 and family 104; six sequences were only detected in ten clones per individual from 3 individuals from family 101; seven sequences were detected in ten clones per individual from one individual from family 101, indicating that this primer set amplifies at least four loci or copies in this species (Table 3) [6, 33]. 
TABLE 3: The number of allele in each of seven flounder families.

\begin{tabular}{|c|c|c|c|c|c|c|}
\hline Individual no. & 1 allele & 2 alleles & 3 alleles & $\begin{array}{l}\text { Allele no } \\
4 \text { alleles }\end{array}$ & 5 alleles & 6 alleles \\
\hline Family 101 & & 6 & 21 & 7 & 2 & 3 \\
\hline Family 104 & & 22 & 8 & 6 & 3 & \\
\hline Family 102 & 3 & 11 & 3 & 3 & & \\
\hline Family 92 & 5 & 6 & 8 & 1 & & \\
\hline Family 75 & 1 & 9 & 9 & 1 & & \\
\hline Family 41 & 3 & 9 & 7 & 1 & & \\
\hline Family 5 & 9 & 6 & 5 & & & \\
\hline Total & 25 & 71 & 57 & 18 & 5 & 3 \\
\hline & $* * *$ & $* * * *$ & $* *$ & $*$ & $* * *$ & $* * * \quad * * * *$ \\
\hline \#Paol-DAB $* 0101$ & ADGFRHYTVA I & DCEFNSS KLN DI EYTQSYYY & NKLEYVRFSS & SVGKYVGYTE Y & YGIKNAERWN NGPEVI ARRG & EKERYCFHNV G IDVEADLT KS \\
\hline \#Paol-DAB $* 0301$ & $\ldots$. Y.V. T & $\ldots \ldots \ldots \ldots \ldots \ldots$ & $\ldots \ldots \ldots$ & $\ldots \ldots \ldots \mathrm{H}$ & Н. ........... & $\ldots \ldots \ldots \ldots$ FT.SA... \\
\hline$\#$ Paol-DAB $* 0801$ & $\ldots \ldots \ldots \mathrm{N}$ & s............ & $\ldots \ldots \ldots$ & $\ldots \ldots \ldots F$ & F..... . ... & $\ldots \ldots \mathrm{R} \ldots \mathrm{N} \ldots \mathrm{A} \ldots$ \\
\hline \#Paol-DAB $* 0901$ & . . .LY.V. T & S........ E. E... & $\ldots$ I. . . & $\ldots \ldots \ldots F$ & F....S. . .... T. & $\ldots \ldots$. . . . \\
\hline \#Paol-DAB $* 4601$ & $\ldots \mathrm{L} \ldots \mathrm{T}$ & $\ldots \ldots \ldots \ldots \ldots$ & $\ldots$ I.... & $\ldots F \ldots F F$ & F....S...Q. .T. . & $\ldots$. . . . \\
\hline \#Paol-DAB $* 2201$ & ...Y.V.G & S........F.L... & $\ldots \ldots$ I $\ldots$ & $\ldots \ldots \ldots \mathrm{H}$ & Н. . . . . . . . TS . & $\ldots$. . . . . VFT. SA ... \\
\hline \#Paol-DAB $* 3201$ & $\ldots \ldots$. . V. N $s$ & S............ & $\ldots \ldots$ I $\ldots$ & $\ldots \ldots \ldots \mathrm{H}$ & H............. A & $\ldots \ldots \mathrm{R} \ldots \mathrm{N} \ldots \mathrm{A} \ldots$ \\
\hline \#Paol-DAB $* 3501$ & ...F.V. T & 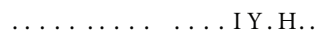 & $\ldots$ I. $\ldots$ & $\ldots \ldots \ldots \mathrm{H}$ & Н. ......... & $\ldots \ldots \mathrm{Y} \ldots \mathrm{V} \ldots \mathrm{A} \ldots$ \\
\hline \#Paol-DAB $* 3801$ & $\ldots \mathrm{L} \ldots \mathrm{MD} s$ & S........ IY.H.. & $\ldots$ I. $\ldots$ & $\ldots F \ldots . V$ & $V \ldots \ldots L \ldots \ldots N \ldots A$ & Q. ...... VFT. . A ... \\
\hline \#Paol-DAB $* 3803$ & $\ldots \mathrm{L} \ldots \mathrm{MD} S$ & S......... IY.H.. & $\ldots \ldots$ I $\ldots$ & $\ldots F \ldots . V$ & $V \ldots \ldots L L \ldots \ldots N \ldots A$ & Q. .......FT.SA... \\
\hline \#Paol-DAB $* 3804$ & $\ldots$ L. .V. D $s$ & S......... IY.H.. & $\ldots \ldots$ I $\ldots$ & $\ldots F \ldots . V$ & $V \ldots \ldots L L \ldots N \ldots A$ & Q. .......FT.SA ... \\
\hline \#Paol-DAB $* 3805$ & $\ldots \mathrm{L} \ldots \mathrm{MD} \mathrm{D}$ & N. . . . . . IY.H.. & $\ldots$ I. $\ldots$ & $\ldots F \ldots . V$ & $V \ldots \ldots L \ldots \ldots T \ldots A$ & Q. . V...... VFT. SA ... \\
\hline \#Paol-DAB $* 4101$ & $\ldots \ldots . M \cdot I$ & E. . . . . F. E... & $\ldots$ FI $\ldots$ & $\ldots F \ldots . \mathrm{H}$ & Н. ............. & 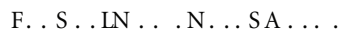 \\
\hline \#Paol-DAB $* 4301$ & ...L. . V. T & $\ldots \ldots \ldots \ldots$ E... & $\ldots$ I I . . . & $\ldots F \ldots$ V & $V \ldots \ldots$ L $\ldots \ldots \ldots A$ & Q. S..LS . . . . SA A. . \\
\hline
\end{tabular}

FIgURE 2: Putative amino acid sequences for MHC II B exon2 alleles of Japanese flounder. Dots denote identity with the first sequences; the putative peptide binding region is indicated with asterisks.

The putative amino acid sequences for the MHC II B exon2 alleles of Japanese flounder along with those previously reported are shown in Figure 2. The nucleotide sequence homology in the MHC class II B genes ranged from $87 \%$ to $99 \%$. Alleles differed in amino acid composition by one to twenty-eight substitutions out of 91 sites.

3.2. Alleles Distribution in the Seven Flounder Families. Alleles were shared among certain individuals and families in this study. Table 4 summarizes the alleles which were frequently present in individuals of the seven families investigated (one allele Paol-DAB*4601 was presented only in this study, while the other 16 alleles have been reported previously [15], and these were Paol-DAB*4301, Paol$D A B^{*}$ 4302, Paol-DAB*0101, Paol-DAB*3201, Paol-DAB* 2201, Paol-DAB*3803, Paol-DAB*3804, Paol-DAB*0102, Paol-DAB*0301, Paol-DAB*4101, Paol-DAB*0801, Paol$D A B^{*}$ 2202, Paol-DAB*0901, Paol-DAB*3805, Paol-DAB* 0502, and Paol-DAB*3501, resp.). Thus, four alleles (Paol$D A B^{*} 4301$, Paol-DAB*0101, Paol-DAB*3201, and Paol$\left.D A B^{*} 2201\right)$ were obtained from three hundred and ninetyseven clones from forty juveniles from family 101, with a frequency of $16 \%, 22.1 \%, 20.3 \%$, and $22.6 \%$, respectively. Five alleles (Paol-DAB*4301, Paol-DAB*4601, Paol-DAB*3803, Paol-DAB*0101, and Paol-DAB*0102) were found to be present in three hundred and ninety-five clones from forty juveniles from family 104, with a frequency of 19.9\%, 20.2\%, $16.4 \%, 19.9 \%$, and $7.3 \%$, respectively. Two alleles (Paol$D A B^{*} 0301$ and Paol-DAB 4101$)$ were obtained from one hundred clones from twenty juveniles from family 5 with a frequency of $6 \%$ and $34 \%$. Four alleles (Paol-DAB*0101, Paol-DAB*0801, Paol-DAB*3803, and Paol-DAB*2202) were present in one hundred and five clones from twenty juveniles in family 41 with a frequency of $21.9 \%, 46.7 \%$, and $22.9 \%$, respectively. Four alleles (Paol-DAB*0901, Paol-DAB*2201, Paol-DAB*3805 and Paol-DAB*0502) were obtained from one hundred and two clones from twenty juveniles in family 75 , with a frequency of $25.5 \%, 22.6 \%, 20.6 \%$, and $15.7 \%$, respectively. Two alleles (Paol-DAB*3501 and Paol$D A B^{*} 4301$ ) were obtained from one hundred and one clones from twenty juveniles family 92 with a frequency of $40.5 \%$ and $43.6 \%$, and three alleles (Paol-DAB ${ }^{*} 0101$, Paol$D A B^{*} 4301$, and Paol-DAB*3803) were presented in ninetyseven clones in twenty juveniles from family 102 with a frequency of $39.2 \%, 24.7 \%$, and $13.4 \%$, respectively.

3.3. Association between Allele Frequency and Resistance/Susceptibility to $V$. anguillarum in the Surviving and Dead Individuals within the Seven Families. Most of the 116 alleles were presented only once or twice and therefore they were excluded from the analysis of the association with bacterial resistance. Fourteen alleles were selected 
TABLE 4: The frequency of alleles $(>3 \%)$ in each of seven families.

\begin{tabular}{|c|c|c|c|c|c|c|c|c|c|}
\hline Allele & Mode & Number & Frequency & Family & Allele & Mode & Number & Frequency & Family \\
\hline \multirow{3}{*}{ Paol-DAB* 0301} & $\mathrm{~S}$ & 21 & $0.21^{* *}$ & \multirow{3}{*}{ F5 } & \multirow{3}{*}{ Paol-DAB* 4101} & $\mathrm{~S}$ & 26 & $0.26^{* *}$ & \multirow{3}{*}{ F5 } \\
\hline & $\mathrm{D}$ & 38 & 0.38 & & & $\mathrm{D}$ & 8 & 0.08 & \\
\hline & Total & 60 & 0.6 & & & Total & 34 & 0.34 & \\
\hline \multirow{3}{*}{ Paol-DAB*0101 } & S & 12 & 0.114 & \multirow{3}{*}{$\mathrm{F} 41$} & \multirow{3}{*}{ Paol-DAB* 0801} & S & 20 & 0.19 & \multirow{3}{*}{ F41 } \\
\hline & $\mathrm{D}$ & 11 & 0.105 & & & $\mathrm{D}$ & 29 & 0.267 & \\
\hline & Total & 23 & 0.219 & & & Total & 49 & 0.467 & \\
\hline \multirow{3}{*}{ Paol-DAB* 3803} & S & 18 & $0.171^{* *}$ & \multirow{3}{*}{ F41 } & \multirow{3}{*}{ Paol-DAB*2202 } & S & 5 & 0.05 & \multirow{3}{*}{ F75 } \\
\hline & $\mathrm{D}$ & 6 & 0.057 & & & $\mathrm{D}$ & 1 & 0.01 & \\
\hline & Total & 24 & 0.229 & & & Total & 6 & 0.059 & \\
\hline \multirow{3}{*}{ Paol-DAB* 0901} & S & 12 & 0.118 & \multirow{3}{*}{ F75 } & \multirow{3}{*}{ Paol-DAB*2201 } & S & 12 & 0.118 & \multirow{3}{*}{ F75 } \\
\hline & $\mathrm{D}$ & 14 & 0.138 & & & $\mathrm{D}$ & 11 & 0.108 & \\
\hline & Total & 26 & 0.255 & & & Total & 23 & 0.226 & \\
\hline \multirow{3}{*}{ Paol-DAB* 3805} & $\mathrm{~S}$ & 12 & 0.118 & \multirow{3}{*}{ F75 } & \multirow{3}{*}{ Paol-DAB* 0502} & S & 7 & 0.069 & \multirow{3}{*}{ F75 } \\
\hline & $\mathrm{D}$ & 9 & 0.088 & & & $\mathrm{D}$ & 9 & 0.088 & \\
\hline & Total & 21 & 0.206 & & & Total & 16 & 0.157 & \\
\hline \multirow{3}{*}{ Paol-DAB* 3501} & S & 16 & 0.158 & \multirow{3}{*}{ F92 } & \multirow{3}{*}{ Paol-DAB* 4301} & S & 25 & 0.248 & \\
\hline & $\mathrm{D}$ & 25 & 0.248 & & & $\mathrm{D}$ & 19 & 0.188 & F92 \\
\hline & Total & 41 & 0.405 & & & Total & 44 & 0.436 & \\
\hline & S & 24 & $0.061^{* *}$ & & & S & 40 & 0.102 & \\
\hline Paol-DAB* 3201 & $\mathrm{D}$ & 56 & 0.142 & F101 & Paol-DAB*0101 & $\mathrm{D}$ & 47 & 0.118 & F101 \\
\hline & Total & 80 & 0.203 & & & Total & 87 & 0.221 & \\
\hline & $S$ & 33 & $0.084^{* *}$ & & & S & 44 & $0.112^{* *}$ & \\
\hline Paol-DAB* 2201 & $\mathrm{D}$ & 56 & 0.142 & F101 & Paol-DAB* 4301 & $\mathrm{D}$ & 19 & 0.048 & F101 \\
\hline & Total & 89 & 0.226 & & & Total & 63 & 0.16 & \\
\hline & S & 8 & 0.02 & & & S & 12 & 0.03 & \\
\hline Paol-DAB*0102 & $\mathrm{D}$ & 9 & 0.023 & F101 & Paol-DAB* 4302 & $\mathrm{D}$ & 2 & 0.005 & F101 \\
\hline & Total & 17 & 0.043 & & & Total & 14 & 0.035 & \\
\hline & $S$ & 30 & 0.076 & & & S & 54 & $0.136^{* *}$ & \\
\hline Paol-DAB* 4301 & $\mathrm{D}$ & 49 & 0.123 & F104 & Paol-DAB* 4601 & $\mathrm{D}$ & 26 & 0.065 & F104 \\
\hline & Total & 79 & 0.199 & & & Total & 80 & 0.202 & \\
\hline & S & 32 & 0.081 & & & S & 43 & 0.108 & \\
\hline Paol-DAB* 3803 & $\mathrm{D}$ & 33 & 0.083 & F104 & Paol-DAB* 0101 & $\mathrm{D}$ & 36 & 0.091 & F104 \\
\hline & Total & 65 & 0.164 & & & Total & 79 & 0.199 & \\
\hline & S & 16 & 0.04 & & & S & 5 & 0.013 & \\
\hline Paol-DAB* 0102 & $\mathrm{D}$ & 13 & 0.033 & F104 & Paol-DAB* 4302 & $\mathrm{D}$ & 13 & 0.033 & F104 \\
\hline & Total & 29 & 0.073 & & & Total & 18 & 0.045 & \\
\hline & $\mathrm{S}$ & 7 & 0.018 & & & S & 7 & 0.072 & \\
\hline Paol-DAB* 3804 & $\mathrm{D}$ & 5 & 0.013 & F104 & Paol-DAB*3803 & $\mathrm{D}$ & 6 & 0.062 & F102 \\
\hline & Total & 12 & 0.03 & & & Total & 13 & 0.134 & \\
\hline & $\mathrm{S}$ & 17 & 0.175 & & Paol-DAB*4301 & S & 12 & 0.124 & \\
\hline Paol-DAB*0101 & $\mathrm{D}$ & 21 & 0.217 & F102 & IUOL-DAD 4501 & $\mathrm{D}$ & 12 & 0.124 & F102 \\
\hline & Total & 38 & 0.392 & & & Total & 24 & 0.247 & \\
\hline
\end{tabular}

Notes: $\mathrm{S}$ denotes survivor individual and $\mathrm{D}$ denotes dead individual in the challenge tests. (One allele Paol-DAB 4601 was first present in this study as well as the other 16 alleles have presented in previous reports [15]). $* *$ denotes difference is significant at the 0.05 level $(P<0.05)$.

for further analysis, of which one allele, Paol-DAB*4601, was first identified in this study, while the 13 other alleles were identified in previous reports [15]. The latter were Paol-DAB*0101, Paol-DAB*0301, Paol-DAB*0801, Paol-DAB* 0901, Paol-DAB*2201, Paol-DAB*3201, Paol$D A B^{*} 3501$, Paol-DAB*3801, Paol-DAB*3803, Paol-DAB*
3804, Paol-DAB*3805, Paol-DAB*4101, and Paol-DAB* 4301. A sharing of the same alleles, Paol-DAB* 4301 and Paol-DAB* 0101, were observed in four of the seven families examined (Table 4), with the frequency different in each family. In family 104, there was a $7.6 \%$ frequency in the surviving individuals and a $12.3 \%$ frequency in dead 
individuals for Paol-DAB* 4301, as well as a $10.8 \%$ frequency in the surviving individuals and a $9.1 \%$ frequency in dead individuals for $\mathrm{Paol}-\mathrm{DA} \mathrm{B}^{*} 0101$. In family 92, there was a $24.8 \%$ frequency for Paol-DAB* 4301 in the survivors and an $18.8 \%$ frequency in the dead individuals. In family 101 , there was an $11.2 \%$ frequency for Paol-DAB* 4301 in survivor individuals and a $4.8 \%$ frequency in dead individuals, and this difference was significant $(P=0.0010)$; there was a $10.2 \%$ frequency found for $\mathrm{Paol}-\mathrm{DA} \mathrm{B}^{*} 0101$ in the surviving individuals and an $11.8 \%$ frequency in the dead. In family 102 , there was a $12.4 \%$ frequency in the surviving and $12.4 \%$ frequency in the dead individuals for Paol-DAB*4301, as well as a $17.5 \%$ frequency in the survivors and a $21.7 \%$ frequency in dead individuals for Paol-DAB*0101. In family 41 , an $11.4 \%$ frequency was found in the surviving individuals while a $10.5 \%$ frequency was found in the dead individuals for Paol-DAB*0101. Some MHC class II B allele frequencies differed significantly between the surviving and dead individuals within the family. In family 104, the Paol-DAB* 4601 allele, which was newly identified in this study, was significantly more frequent in the surviving $(13.6 \%)$ individuals than in the dead individuals $(6.5 \%$, $P=0.001)$.

In family 101, the Paol-DAB*2201 frequency in the surviving individuals $(8.4 \%)$ was significantly lower than in the dead individuals $(14.2 \%, P=0.001)$, while in family 41 , the Paol-DAB* 3803 allele was significantly more frequent in the survivors $(17.1 \%)$ than the dead $(5.7 \%, P=0.009)$. In family 5, the Paol-DAB* 4101 allele was significantly more frequent in the surviving $(26 \%)$ than dead fish $(8 \%, P=$ 0.01 ), while the $P a o l-D A B^{*} 0301$ allele was significantly more frequent in the dead $(38 \%)$ than the survivors $(21 \%, P=$ 0.008 ). In family 75 , family 92 , and family 102 , the difference between the allele frequencies in the surviving and dead individuals was not significant. These results suggested that the Paol-DAB* 4301, Paol-DAB* 4601, Paol-DAB*4302, Paol$D A B^{*} 3803$, and Paol-DAB* 4101 alleles were associated with resistance to V. anguillarum, while Paol-DAB* 2201 and Paol$D A B^{*} 0301$ appeared to be associated with susceptibility to this bacteria.

3.4. Evidence for Balancing Selection. The pattern of nucleotide substitution was examined in the putative PBR (peptide-binding region) and other regions. Twenty-three amino acid residues were selected as the putative PBR sites in the human regions [34]. The mean numbers of synonymous substitutions per synonymous site $\left(d_{S}\right)$ and nonsynonymous substitutions per nonsynonymous site $\left(d_{N}\right)$ were based on pairwise comparisons among the whole sequences in seven families (Table 5). In the putative PBR region, the mean $d_{N}$ $(0.231,0.134,0.109,0.180,0.167,0.146,0.147$, and 0.177$)$ was significantly higher than the mean $d_{S}(0.037,0.031$, $0.048,0.060,0.024,0.009,0.024$, and 0.004 ) for all of the pairwise comparisons, respectively. Furthermore the $d_{N} / d_{S}$ in the $\operatorname{PBR}(6.243,4.323,2.271,3.000,6.96,16.2,6.125$, 44.25) was greater than that in the non-PBR (1.390, 2.5, $1.109,1.065,1.27,1.410,1.606,1.389)$ in terms of the whole sequence and in each family sequence, respectively. These results indicated that positive selection was at work in the PBR of MHC class II B genes.
3.5. Inheritance of the Allele in the Next Generation. The pedigree of the Japanese flounder was shown in Figure 1. At $\mathrm{G}_{1}$, both family 0768 and family 0751 had Paol-DAB* 4301 alleles, while family 0768 also had Paol-DAB*0801 allele. We found that the Paol-DAB* 4301 alleles were presented in families $101,104,92$, and 102, and Paol-DAB*0801 in family 41 at $G_{2}$, respectively. The sire and dam of family 92 were from family 0751, while the sire and dam of family 101 were from family 0743 and family 0751 , respectively. The sire and dam of family 102 were from family 0768. The sire and dam of family 41 were from family 0768 and family R7, respectively, while the sire and dam of family 104 were from family 0768 and family 0719 , respectively. This denoted that the MHC II B alleles were passed on to the progeny. Neither Paol-DAB* 4301 nor Paol-DAB*0801 was present in family 75 and 5 . The sire and dam of family 75 were from family 0743 and 0750 , respectively, while the sire and dam of family 5 were both from family 0750 . The distribution patterns of the alleles in each family were obtained from DNA sequence analysis and are shown in Table 4.

\section{Discussion}

The major histocompatibility complex (MHC) is a vital portion of the vertebrate immune system, and MHC allele diversity is critical for resistance against parasites [14]. Dixon et al. [35] discovered 57 alleles in 17 individuals with greater polymorphism than is found in most mammals. This region was selected for amplification as a result of it covering the whole of exon 2 in the $\beta 1$ domain, which corresponded to the highly variable region of the PBR. Therefore, in this study, we investigated variations in seven flounder families using MHC class II B exon2 as a gene marker, and the diversity was found to differ significantly (116 sequences in 180 individuals). At least four MHC class II exon2 loci were present in Japanese flounders, which was more than the number previously reported by $\mathrm{Xu}$ et al. [15] and Zhang et al. [20]. Homology of these alleles from each individual was from $89 \%$ to $100 \%$, and in all the individuals examined was from $87 \%$ to $100 \%$, with levels as high as 0.11 in mammals [36].

In a previous study by $\mathrm{Xu}$ et al. [15], Paol-DAB*4301, Paol-DAB* 0601, Paol-DAB* 0801, Paol-DAB*2001, and Paol$D A B^{*} 3803$ were the alleles which found to be associated with resistance to $V$. anguillarum, while Paol-DAB*1601, Paol$D A B^{*} 2201$, and Paol-DAB* 2701 were the alleles which associate with susceptibility. In the present study, we found that Paol-DAB* 4301, Paol-DAB* 4601, Paol-DAB*3803, and Paol$D A B^{*} 4101$ were associated with resistance to $V$. anguillarum, while Paol-DAB*3201, Paol-DAB*2201, and Paol-DAB*0301 alleles were associated with susceptibility. Moreover, the significant difference in the frequency of each allele between the survivors and dead fish was only found in one family.

In addition to the fact that analysis within family was less influenced by the background of the families' genetic variations. The link between the alleles and the bacterial resistance was unpredictable both within and among families, as well as the pooled material. It might be that the alleles are indirectly involved in the resistance to pathogens, or it was possible 
TABLe 5: Synonymous $\left(d_{S}\right)$ and nonsynonymous $\left(d_{N}\right)$ substitution rate in the putative peptides binding region (PBR) and nonpeptides binding region (non-PBR) among Japanese flounder families.

\begin{tabular}{|c|c|c|c|c|c|}
\hline Family & Region & No. of codons & $d_{N}(\mathrm{SE})$ & $d_{S}(\mathrm{SE})$ & $d_{N} / d_{S}$ \\
\hline \multirow{3}{*}{ F5 } & PBR & 23 & $0.134 \pm 0.037$ & $0.031 \pm 0.022$ & 4.323 \\
\hline & Non-PBR & 68 & $0.04 \pm 0.012$ & $0.016 \pm 0.009$ & 2.5 \\
\hline & Total & 91 & $0.064 \pm 0.014$ & $0.019 \pm 0.008$ & 3.368 \\
\hline \multirow{3}{*}{ F41 } & PBR & 23 & $0.109 \pm 0.023$ & $0.048 \pm 0.024$ & 2.271 \\
\hline & Non-PBR & 68 & $0.051 \pm 0.014$ & $0.046 \pm 0.018$ & 1.109 \\
\hline & Total & 91 & $0.066 \pm 0.013$ & $0.046 \pm 0.014$ & 1.435 \\
\hline \multirow{3}{*}{ F92 } & PBR & 23 & $0.180 \pm 0.034$ & $0.060 \pm 0.041$ & 3.000 \\
\hline & Non-PBR & 68 & $0.033 \pm 0.010$ & $0.031 \pm 0.015$ & 1.065 \\
\hline & Total & 91 & $0.069 \pm 0.015$ & $0.037 \pm 0.016$ & 1.865 \\
\hline \multirow{3}{*}{ F75 } & PBR & 23 & $0.167 \pm 0.032$ & $0.024 \pm 0.013$ & 6.96 \\
\hline & Non-PBR & 68 & $0.047 \pm 0.012$ & $0.037 \pm 0.018$ & 1.27 \\
\hline & Total & 91 & $0.078 \pm 0.013$ & $0.034 \pm 0.013$ & 2.294 \\
\hline \multirow{3}{*}{ F102 } & PBR & 23 & $0.146 \pm 0.035$ & $0.009 \pm 0.009$ & 16.2 \\
\hline & Non-PBR & 68 & $0.055 \pm 0.013$ & $0.039 \pm 0.013$ & 1.410 \\
\hline & Total & 91 & $0.079 \pm 0.013$ & $0.032 \pm 0.013$ & 2.469 \\
\hline \multirow{3}{*}{ F101 } & PBR & 23 & $0.147 \pm 0.030$ & $0.024 \pm 0.007$ & 6.125 \\
\hline & Non-PBR & 68 & $0.053 \pm 0.013$ & $0.033 \pm 0.014$ & 1.606 \\
\hline & Total & 91 & $0.077 \pm 0.014$ & $0.031 \pm 0.010$ & 2.484 \\
\hline \multirow{3}{*}{ F104 } & PBR & 23 & $0.177 \pm 0.028$ & $0.004 \pm 0.004$ & 44.25 \\
\hline & Non-PBR & 68 & $0.050 \pm 0.013$ & $0.036 \pm 0.014$ & 1.389 \\
\hline & Total & 91 & $0.083 \pm 0.014$ & $0.028 \pm 0.011$ & 2.964 \\
\hline \multirow{3}{*}{ Whole } & PBR & 23 & $0.231 \pm 0.051$ & $0.037 \pm 0.028$ & 6.243 \\
\hline & Non-PBR & 68 & $0.057 \pm 0.020$ & $0.041 \pm 0.023$ & 1.390 \\
\hline & Total & 91 & $0.098 \pm 0.020$ & $0.038 \pm 0.018$ & 2.579 \\
\hline
\end{tabular}

that the families which were challenged displayed different but "functionally similar" alleles by chance.

$\mathrm{Xu}$ et al. [15] demonstrated that the MHC II B alleles were passed on to the progeny. In the present study, the allele Paol-DAB* 4301 in family 0768 at $\mathrm{G}_{1}$ was also discovered in families 101, 104, 92, and 102 at $G_{2}$. This stability of inheritance within the families had been shown for two generations. Klein [37] reported that the high levels of allelic diversity and polymorphism in the $\mathrm{MHC}$ resulted from the long-term coevolution of parasites and MHC molecules. In this study, no complete sequences (alleles) were shared across all of the families, while certain alleles were shared among individuals and two to three families in the Japanese flounder. The sequences of the MHC alleles were not consistent with the phylogeny relationships of individuals seen as a family. This was in agreement with the result of Ye et al. [38], who reported that the MHC allele sequences were not consistent with the phylogeny relationships of a population in a closely related species. Therefore, to fully understand the polymorphism of the MHC class II genes in Japanese flounder, it was necessary to carry further studies, including an estimation of the number of gene loci, introductions of improved methods, and analysis of a greater number of individuals as well as genes and functions. Genetic polymorphism of MHC was generally thought to be maintained by a balancing selection driven by host-parasite coevolution
[39-42]. Evidence for balancing selection operating in the MHC class II B gene was a significantly higher rate of non-synonymous mutation $\left(d_{N} / d_{S}>1\right)$, which indicated that the rate of non-synonymous substitution per nonsynonymous sites exceeds that of synonymous substitution per synonymous sites $[43,44]$.

We examined the Paol-DAB alleles, including both the whole sequences and the sequences in each family discovered in the present study and found that the $d_{N} / d_{S}$ ratio $(6.234$, $4.323,2.271,3.000,6.96,16.2,6.125$, and 44.25 , resp.) in the putative PBR regions was higher than that of $d_{N} / d_{S}(1.390$, $2.5,1.109,1.065,1.27,1.410,1.606$, and 1.389 , resp.) in the non-PBR regions in the MHC class II exon2 domain of Japanese flounder (Table 5), as was also the case for the human, nonhuman primate, and mouse class II genes[4446]. This was evidence for balancing selection or positive selection at work in the PBR of MHC class II B genes. In this study, certain alleles exhibited a high frequency in individual families (Table 4), while other alleles were found only once or twice in seven families, which indicated frequency-dependent selection $[17,47]$, that is, one model of balancing selection, acting on the polymorphism of the MHC class II B genes in the Japanese flounder.

In the seven families investigated, the percentage of heterozygosity (two different sequences in one individual) in families $101,104,102,92,75,41$, and family 5 is $100 \%, 100 \%$, 
$85 \%, 75 \%, 95 \%, 85 \%$, and 55\%, respectively. All but one of these corresponds to the level of heterozygosity in humans and mice, which was in a range of $80-90 \%$ [48]. The sire and dam of family 92 were from family 0751, the sire and dam of family 5 were from family 0750 , and sire and dam of family 102 were from family 0768 . These exhibited lower heterozygosity $(75 \%, 55 \%, 85 \%)$, especially family 5 with the lowest heteroxygosity (55\%), but the survival ratio of family 5 was the highest among the seven families examined in this study. It might indicate that other genes in family 5 or the homozygosity of the MHC class II B gene resulted in the resistance to $V$. anguillarum in the Japanese flounder. Further studies are needed to examine the MHC class II B genes in the offspring of the seven families reported in this study.

Between 5 and 10 clones in each of the individual PCR products had one or seven sequences, and most of these sequences were the same as that of the other clones, indicating that some of these were not the result of PCR amplification "errors" [49] or the mismatch repair of heteroduplex molecules during the course of cloning in $E$. coli. [50]. In this study, ten (20 individuals from family 101 and 104 , resp.) or five (10 individuals from family 5, 41, 75, 92 and 102, resp.) clones per individual were sequenced, and we found a significant difference in the allele distribution in the surviving and dead individuals in each of the seven families. It was possible that the results would differ in terms of the clones and samples, so further studies were needed to select a greater number of both for sequencing and analysis.

In summary, the detection of MHC class II B alleles and their polymorphisms as depicted in the present study will be helpful for immunological research in the future. This investigative work has the ultimate aim of developing families or strains of Japanese flounder with bacterial resistance.

\section{Acknowledgments}

This work was supported by the National Major Basic Research Program of China (2010CB126303), Special Fund for Agroscientific Research in the Public Interest (200903046), the National Natural Science Foundation of China (30871918), and Taishan scholar project of Shandong province, China.

\section{References}

[1] R. Sheng, X. X. Xu, Q. Tang et al., "Polysaccharide of radix pseudostellariae improves chronic fatigue syndrome induced by poly I:C in mice," Evidence-Based Complementary and Alternative Medicine. In press.

[2] R. N. Germain, "MHC-dependent antigen processing and peptide presentation: providing ligands for $\mathrm{T}$ lymphocyte activation," Cell, vol. 76, no. 2, pp. 287-299, 1994.

[3] J. Bingulac-Popovic, F. Figueroa, A. Sato et al., "Mapping of Mhc class I and class II regions to different linkage groups in the zebrafish, Danio rerio," Immunogenetics, vol. 46, no. 2, pp. 129-134, 1997.

[4] A. Sato, F. Figueroa, B. W. Murray et al., "Nonlinkage of major histocompatibility complex class I and class II loci in bony fishes," Immunogenetics, vol. 51, no. 2, pp. 108-116, 2000.
[5] J. D. Hansen, P. Strassburger, G. H. Thorgaard, W. P. Young, and L. Du Pasquier, "Expression, linkage, and polymorphism of MHC-related genes in rainbow trout, Oncorhynchus mykiss," Journal of Immunology, vol. 163, no. 2, pp. 774-786, 1999.

[6] K. Hashimoto, T. Nakanishi, and Y. Kurosawa, "Isolation of carp genes encoding major histocompatibility complex antigens," Proceedings of the National Academy of Sciences of the United States of America, vol. 87, no. 17, pp. 6863-6867, 1990.

[7] J. Nikolich-Žugich, D. H. Fremont, M. J. Miley, and I. Messaoudi, "The role of mhc polymorphism in anti-microbial resistance," Microbes and Infection, vol. 6, no. 5, pp. 501-512, 2004.

[8] N. Otting, N. G. de Groot, G. G. M. Doxiadis, and R. E. Bontrop, "Extensive Mhc-DQB variation in humans and nonhuman primate species," Immunogenetics, vol. 54, no. 4, pp. 230-239, 2002.

[9] K. Musolf, Y. Meyer-Lucht, and S. Sommer, "Evolution of MHC-DRB class II polymorphism in the genus Apodemus and a comparison of DRB sequences within the family Muridae (Mammalia: Rodentia)," Immunogenetics, vol. 56, no. 6, pp. 420-426, 2004.

[10] H. C. Miller, K. Belov, and C. H. Daugherty, "Characterization of MHC class II genes from an ancient reptile lineage, Sphenodon (tuatara)," Immunogenetics, vol. 57, no. 11, pp. 883-891, 2005.

[11] Y. Shi, W. Xiao-bing, Y. Peng, and C. Bi-hui, "Cloning and sequences analysis of the second exon of MHC class II B genes in Chinese alligator, Alligator sinensis," Zoological Research, vol. 25, pp. 415-421, 2004.

[12] D. H. Bos and J. A. DeWoody, "Molecular characterization of major histocompatibility complex class II alleles in wild tiger salamanders (Ambystoma tigrinum)," Immunogenetics, vol. 57, no. 10, pp. 775-781, 2005.

[13] S. Consuegra, H. J. Megens, K. Leon, R. J. M. Stet, and W. C. Jordan, "Patterns of variability at the major histocompatibility class II alpha locus in Atlantic salmon contrast with those at the class I locus," Immunogenetics, vol. 57, no. 1-2, pp. 16-24, 2005.

[14] K. M. Wegner, M. Kalbe, G. Rauch, J. Kurtz, H. Schaschl, and T. B. H. Reusch, "Genetic variation in MHC class II expression and interactions with MHC sequence polymorphism in threespined sticklebacks," Molecular Ecology, vol. 15, no. 4, pp. 1153-1164, 2006.

[15] T. J. Xu, S. L. Chen, X. S. Ji, and Y. S. Tian, "MHC polymorphism and disease resistance to Vibrio anguillarum in 12 selective Japanese flounder (Paralichthys olivaceus) families," Fish and Shellfish Immunology, vol. 25, no. 3, pp. 213-221, 2008.

[16] A. L. Hughes and M. Nei, "Models of host-parasite interaction and MHC polymorphism," Genetics, vol. 132, no. 3, pp. 863864, 1992.

[17] R. W. Slade and H. I. McCallum, "Overdominant vs. frequency-dependent selection at MHC loci," Genetics, vol. 132, no. 3, pp. 861-862, 1992.

[18] P. W. Hedrick, "Balancing selection and MHC," Genetica, vol. 104, no. 3, pp. 207-214, 1998.

[19] P. Srisapoome, T. Ohira, I. Hirono, and T. Aoki, "Cloning, characterization and expression of cDNA containing major histocompatibility complex class I, II $\alpha$ and II $\beta$ genes of Japanese flounder Paralichthys olivaceus," Fisheries Science, vol. 70, no. 2, pp. 264-276, 2004. 
[20] Y. X. Zhang, S. L. Chen, Y. G. Liu, Z. X. Sha, and Z. J. Liu, "Major histocompatibility complex class IIB allele polymorphism and its association with resistance/susceptibility to Vibrio anguillarum in Japanese flounder (Paralichthys olivaceus)," Marine Biotechnology, vol. 8, no. 6, pp. 600-610, 2006.

[21] S. L. Chen, Y. S. Tian, T. J. Xu, H. Deng, B. W. Liu, and G. C. Yu, "Development and characterization for growth rate and disease resistance of disease-resistance population and family in Japanese flounder (Paralichthys olivaceus)," Journal of Fisheries of China, vol. 32, no. 5, pp. 665-673, 2008.

[22] Y. Palti, J. T. Silverstein, H. Wieman, J. G. Phillips, F. T. Barrows, and J. E. Parsons, "Evaluation of family growth response to fishmeal and gluten-based diets in rainbow trout (Oncorhynchus mykiss)," Aquaculture, vol. 255, no. 1-4, pp. 548-556, 2006.

[23] P. Zylstra, H. S. Rothenfluh, G. F. Weiller, R. V. Blanden, and E. J. Steele, "PCR amplification of murine immunoglobulin germline $\mathrm{V}$ genes: strategies for minimization of recombination artefacts," Immunology and Cell Biology, vol. 76, no. 5, pp. 395-405, 1998.

[24] K. Tamura, J. Dudley, M. Nei, and S. Kumar, "MEGA4: Molecular Evolutionary Genetics Analysis (MEGA) software version 4.0," Molecular Biology and Evolution, vol. 24, no. 8, pp. 1596-1599, 2007.

[25] M. Nei and T. Gojobori, "Simple methods for estimating the numbers of synonymous and nonsynonymous nucleotide substitutions," Molecular Biology and Evolution, vol. 3, no. 5, pp. 418-426, 1986.

[26] T. H. Jukes and C. R. Cantor, "Evolution of protein molecules," in Mammalian Protein Metabolism, H. N. Munro, Ed., pp. 21132, Academic Press, New York, NY, USA, 1969.

[27] P. Librado and J. Rozas, "DnaSP v5: a software for comprehensive analysis of DNA polymorphism data," Bioinformatics, vol. 25, no. 11, pp. 1451-1452, 2009.

[28] X. Xia and Z. Xie, "DAMBE: software package for data analysis in molecular biology and evolution," Journal of Heredity, vol. 92, no. 4, pp. 371-373, 2001.

[29] W. R. Rice, “Analysis tables of statistical tests," Evolution, vol. 43, pp. 223-225, 1989.

[30] R. F. Xu, K. Li, G. H. Chen, Y. Z. Qiang, Y. B. Zhang, and L. Lin, "Genetic variation within exon 2 of the MHC B-LB II gene inTibetan chicken," Acta Genetica Sinica, vol. 32, no. 11, pp. 1136-1146, 2005.

[31] S. G. Antunes, N. G. De Groot, H. Brok et al., "The common marmoset: a new world primate species with limited Mhc class II variability," Proceedings of the National Academy of Sciences of the United States of America, vol. 95, no. 20, pp. 1174511750, 1998.

[32] K. Trtková, H. Kupfermann, B. Grahovac et al., "Mhc-DRB genes of platyrrhine primates," Immunogenetics, vol. 38, no. 3, pp. 210-222, 1993.

[33] D. Klein, H. Ono, C. O'hUigin, V. Vincek, T. Goldschmidt, and J. Klein, "Extensive MHC variability in cichlid fishes of Lake Malawi," Nature, vol. 364, no. 6435, pp. 330-334, 1993.

[34] J. H. Brown, T. S. Jardetzky, J. C. Gorga et al., "Threedimensional structure of the human class II histocompatibility antigen HLA-DR1," Nature, vol. 364, no. 6432, pp. 33-39, 1993.

[35] B. Dixon, L. A. J. Nagelkerke, F. A. Sibbing, E. Egberts, and R. J. M. Stet, "Evolution of MHC class II $\beta$ chain-encoding genes in the Lake Tana barbel species flock (Barbus intermedius complex)," Immunogenetics, vol. 44, no. 6, pp. 419-431, 1996.
[36] M. Nei and A. L. Hughes, "Polymorphism and evolution of the major histocompatibility complex loci in mammals," in Evolution at the Molecular Level, R. K. Selander, A. G. Clark, and T. S. Whittam, Eds., pp. 222-247, Sinauer Associates, Sunderland, UK, 1991.

[37] J. Klein, "Of HLA, tryps, and selection: an essay on coevolution of MHC and parasites," Human Immunology, vol. 30, no. 4, pp. 247-258, 1991.

[38] Y. Ye, J. She, and E. K. Wakeland, "Diversification of class II A within the genus Mus," in Molecular Evolution of the Major Histocompatibility Complex, J. Klein and D. Klein, Eds., pp. 131-138, Springer, Berlin, Germany, 1991.

[39] J. A. Eimes, J. L. Bollmer, P. O. Dunn, L. A. Whittingham, and C. Wimpee, "Mhc class II diversity and balancing selection in greater prairie-chickens," Genetica, vol. 138, no. 2, pp. 265$271,2010$.

[40] S. B. Piertney and M. K. Oliver, "The evolutionary ecology of the major histocompatibility complex," Heredity, vol. 96, no. 1, pp. 7-21, 2006.

[41] L. Bernatchez and C. Landry, "MHC studies in nonmodel vertebrates: what have we learned about natural selection in 15 years?" Journal of Evolutionary Biology, vol. 16, no. 3, pp. 363-377, 2003.

[42] T. Strand, H. Westerdahl, J. Höglund, R. V. Alatalo, and H. Siitari, "The Mhc class II of the Black grouse (Tetrao tetrix) consists of low numbers of $\mathrm{B}$ and $\mathrm{Y}$ genes with variable diversity and expression," Immunogenetics, vol. 59, no. 9, pp. 725-734, 2007.

[43] A. L. Hughes and M. Nei, "Pattern of nucleotide substitution at major histocompatibility complex class I loci reveals overdominant selection," Nature, vol. 335, no. 6186, pp. 167170, 1988.

[44] A. L. Hughes and M. Nei, "Nucleotide substitution at major histocompatibility complex class II loci: evidence for overdominant selection," Proceedings of the National Academy of Sciences of the United States of America, vol. 86, no. 3, pp. 958962, 1989.

[45] T. Bergström and U. Gyllensten, "Evolution of the Mhc class II polymorphism: the rise and fall of class II gene function in primates," Immunological Reviews, no. 143, pp. 14-31, 1995.

[46] E. Medina and R. J. North, "Resistance ranking of some common inbred mouse strains to Mycobacterium tuberculosis and relationship to major histocompatibility complex haplotype and Nramp1 genotype," Immunology, vol. 93, no. 2, pp. 270274, 1998.

[47] N. Takahata and M. Nei, "Allelic genealogy under overdominant and frequency-dependent selection and polymorphism of major histocompatibility complex loci," Genetics, vol. 124, no. 4, pp. 967-978, 1990.

[48] J. Klein, Natural History of the Major Histocompatibility Complex, John Wiley \& Sons, New York, NY, USA, 1986.

[49] P. D. Ennis, J. Zemmour, R. D. Salter, and P. Parham, "Rapid cloning of HLA-A,B cDNA by using the polymerase chain reaction: frequency and nature of errors produced in amplification," Proceedings of the National Academy of Sciences of the United States of America, vol. 87, no. 7, pp. 2833-2837, 1990.

[50] M. Longeri, M. Zanotti, and G. Damiani, "Recombinant DRB sequences produced by mismatch repair of heteroduplexes during cloning in Escherichia coli," European Journal of Immunogenetics, vol. 29, no. 6, pp. 517-523, 2002. 


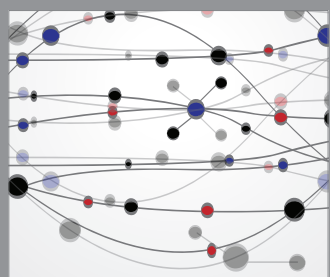

The Scientific World Journal
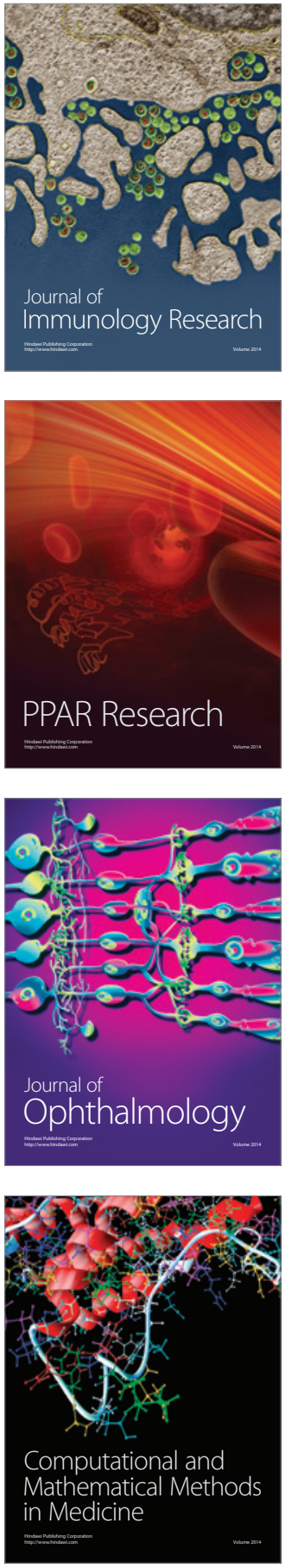

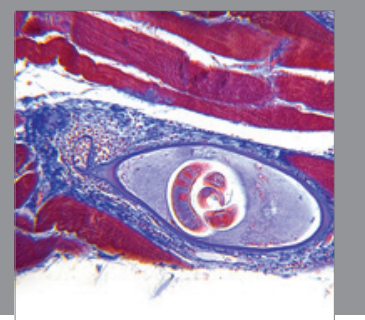

Gastroenterology

Research and Practice
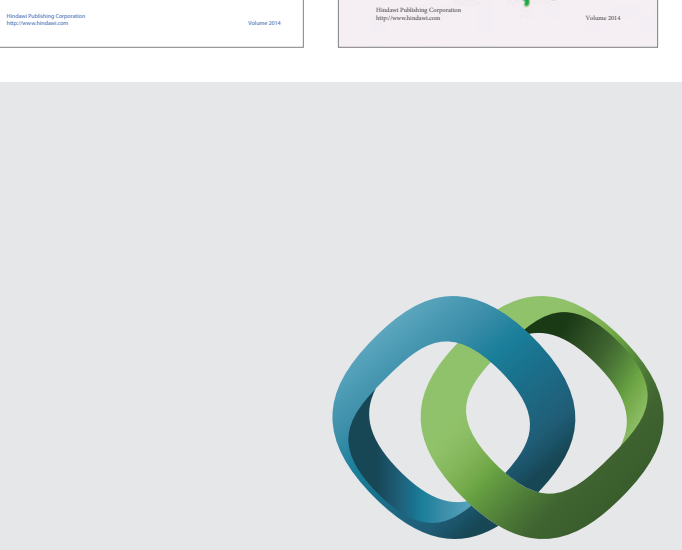

\section{Hindawi}

Submit your manuscripts at

http://www.hindawi.com
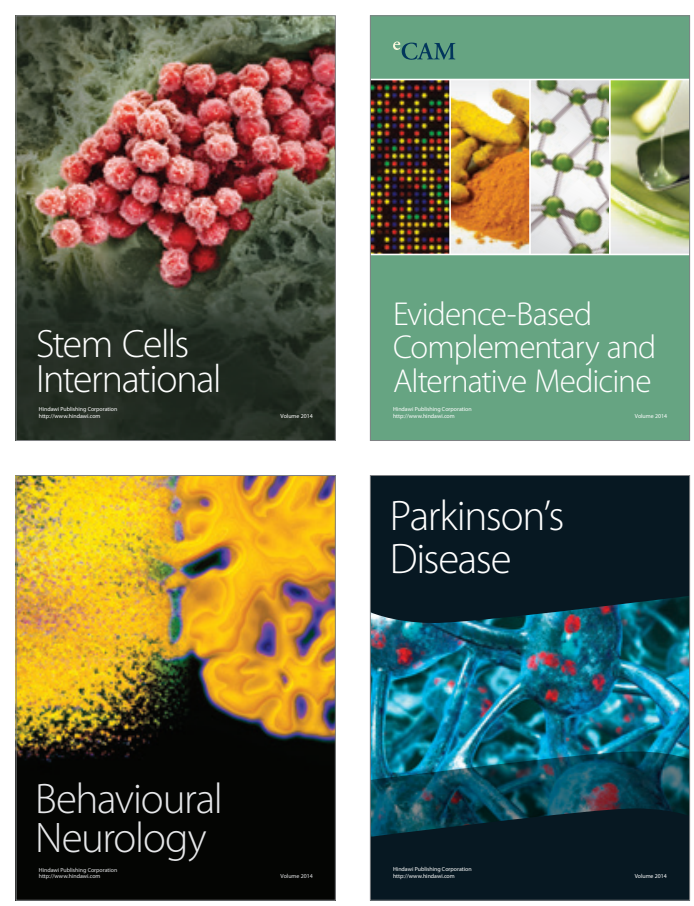

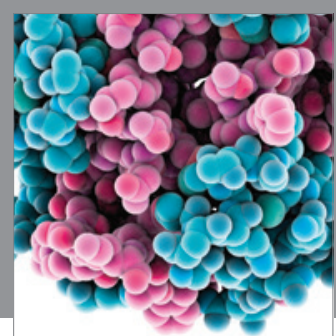

Journal of
Diabetes Research

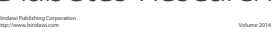

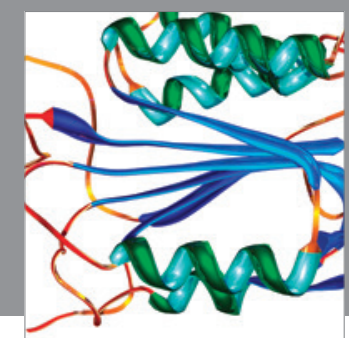

Disease Markers
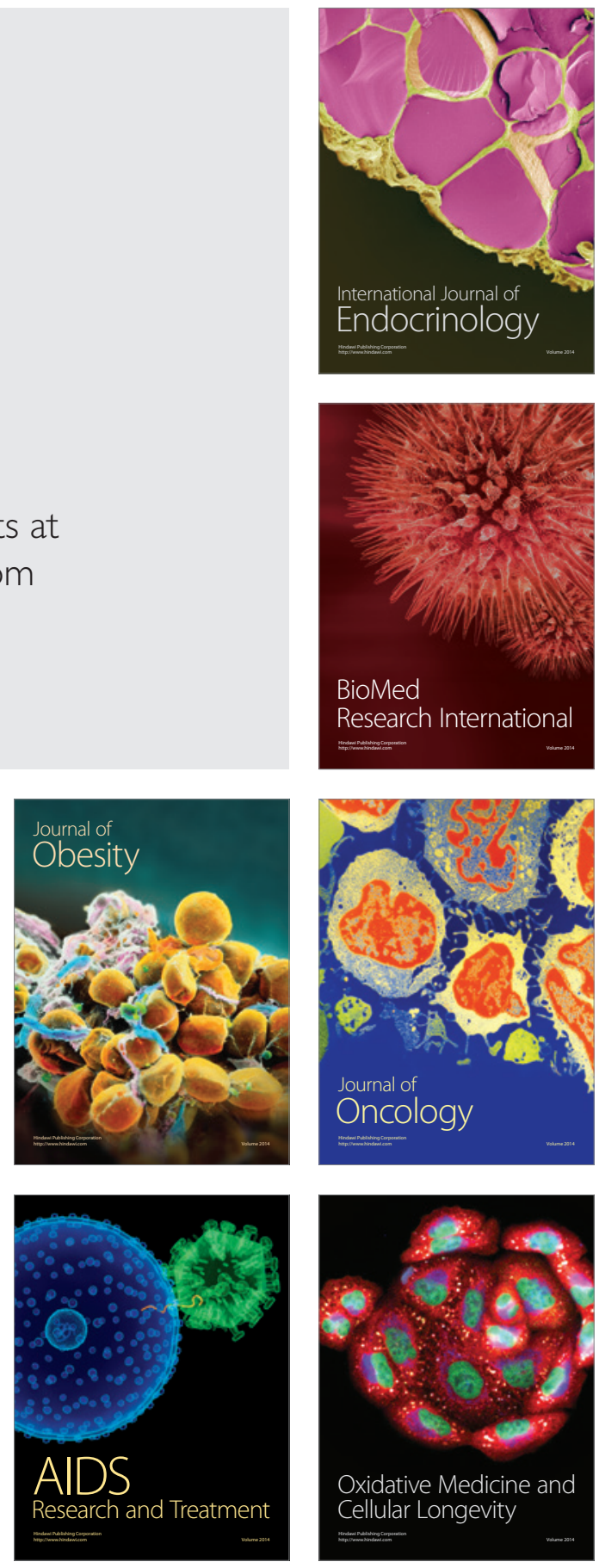